\title{
GERMINAÇÃO E VIGOR DE PLANTAS DE MARACUJAZEIRO 'AMARELO'EM DIFERENTES ESTÁDIOS DE MATURAÇÃO DO FRUTO, ARILO E SUBSTRATO
}

\author{
Germination and vigor of passion fruit seeds in different estages of fruit maturation, \\ substrate and presence or the aril
}

\author{
José Carlos Lopes ${ }^{1}$, Gustavo Marchezi Bono², Rodrigo Sobreira Alexandre ${ }^{3}$, Victor Martins Maia ${ }^{4}$
}

\begin{abstract}
RESUMO
O conhecimento dos efeitos de substratos, do estádio de maturação dos frutos e da presença do arilo sobre a germinação das sementes do maracujá é de suma importância para o desenvolvimento desta cultura. Portanto, o objetivo deste trabalho foi estudar a germinação e o vigor de plantas de maracujazeiro 'amarelo' (Passiflora edulis Sims.f. flavicarpa Degener) em diferentes estádios de maturação do fruto, arilo e substrato. $\mathrm{O}$ delineamento experimental utilizado foi o inteiramente casualizado, com 4 repetições de 25 sementes, em esquema fatorial 2 × 2 × 3, com 2 estádios de maturação do fruto (maduro e murcho), presença e ausência do arilo e 3 substratos (vermiculita, areia e areia + terra + esterco (bovino). As características avaliadas foram: germinação, índice de velocidade de emergência, plântulas normais e anormais, sementes duras e deterioradas e massa seca da parte aérea e da raiz (mg). As sementes de frutos murchos apresentaram maior porcentagem de germinação, acontecendo o mesmo quando se fez a remoção do arilo. A velocidade de emergência das plântulas foi favorecida pelo plantio de sementes de frutos murchos com arilo no substrato areia + terra + esterco.
\end{abstract}

Termos para indexação: Passiflora edulis Sims. f. flavicarpa Degener, maracujá, propagação.

\begin{abstract}
The knowledge of substrate effects, stages of fruits maturation and presence of the aril on the passion fruit seeds germination is importante for development of this culture. Therefore, the objective of this work was to study the germination and vigor of passion fruit seed on different stages of fruits maturation, substrate and presence of the aril. An experiment was set up on an entirely randomized design following a factorial arrangement of $2 \times 2 \times 3$, with four replications of 25 seeds, in order to determine the effects of two stages of fruit maturation (ripe and withered), presence and absence of aril and three substrate (vermiculite, sand and soil+sand+dung (bovine). Evaluation were performed for the germination (\%); index of emergency speed; normal and abnormal seedlings (\%); hard seeds and deteriorated (\%) and mass dries of aerial part and of root (mg). The seeds of (vermiculite, sand and soil+sand+dung (bovine). Evaluation were performed for the germination (\%); index of emergency speed; normal and abnormal seedlings (\%); hard seeds and deteriorated (\%) and mass dries of aerial part and of root (mg). The withered fruits presented larger germination percentage, happening the same when it was made the removal of the arilo. The speed of emergency of the seedlings was favored by the planting of seeds of withered fruits with aril in the soil + sand + dung substrate.
\end{abstract}

Index terms: Passiflora edulis Sims. f. flavicarpa Degener, passion fruit, propagation.

(Recebido em 10 de janeiro de 2006 e aprovado em 6 de julho de 2006)

\section{INTRODUÇÃO}

O conhecimento das condições ideais para a germinação, principalmente o tipo de substrato, é de suma importância, pois fatores como estrutura, aeração, capacidade de retenção de água, grau de infestação de patógenos, dentre outros, podem interferir na germinação das sementes e desenvolvimento pós-seminal (CARVALHO \& NAKAGATA, 2000). Silva et al. (2001) também relataram no trabalho sobre a influência de diversos substratos no desenvolvimento de mudas do maracujazeiro (Passiflora edulis f. flavicarpa Deg.), que os melhores substratos devem ser ausentes de patógenos, ricos em nutrientes essenciais, com $\mathrm{pH}$, textura e estrutura adequados. Dentre estas características, a presença de patógenos pode interferir mais no processo germinativo das sementes.

Sementes de maracujá amarelo, oriundas de frutos de 70 e 77 dias de idade (da antese à colheita), foram mais vigorosas que as demais e, nestas idades, o tegumento já se apresentava completamente escurecido e as sementes maduras morfologicamente (ALMEIDA et al., 1988).

\footnotetext{
'Engenheiro Agrônomo, D.Sc., Professor Associado - Departamento Produção Vegetal - Centro de Ciências Agrárias - Universidade Federal do Espírito Santo/CCA-UFES - Alto Universitário, s/n - Cx. P. 16 - 29500-000 - Alegre, ES - jclopes@cca.ufes.br

²Engenheiro Agrônomo - Venda Nova Agropecuária LTDA - Avenida Ângelo Altoé, №144 - Centro - Venda Nova do Imigrante, ES - 29.375-000 nutrienes@uol.com.br

${ }^{3}$ Engenheiro Agrônomo, D.Sc., Bolsista de Pós-Doctor/CNPq - Universidade Federal de Viçosa/UFV - Departamento de Fitotecnia - Av. P.H. Rolfs, s/n - 36570-000 - Viçosa, MG - rsalexandre@click21.com.br

${ }^{4}$ Engenheiro Agrônomo, D.Sc., Professor Adjunto - Universidade Estadual de Montes Claros/UNIMONTES - Centro de Ciências Exatas e Tecnológicas Departamento de Ciências Agrárias - Rua Reinaldo Viana, 2630 - Campus Universitário de Janaúba - Bico da Pedra - $39440-000$ - Janaúba, MG victor.maia@unimontes.br
} 
São José \& Nakagawa (1987) observaram que a presença do arilo nas sementes contribuiu para reduzir a porcentagem de germinação das sementes do maracujazeiro. Assim, com o objetivo de proporcionar uma uniformidade na germinação, outros autores também estudaram métodos de remoção da mucilagem nas sementes do maracujazeiro (ALMEIDA et al., 1988; CARDOSO et al., 2001; MELETTI \& MAIA, 1999; PEREIRA \& DIAS, 2000; SANTOS et al., 1999).

Com este trabalho, objetivou-se estudar a germinação e o vigor de plantas de maracujazeiro 'amarelo' (Passiflora edulis Sims. f. flavicarpa Degener) em diferentes estádios de maturação do fruto, arilo e substrato.

\section{MATERIAL E MÉTODOS}

O experimento foi conduzido no Laboratório de Tecnologia e Análise de Sementes do Departamento de Fitotecnia do Centro de Ciências Agrárias da Universidade Federal do Espírito Santo (CCA-UFES), em Alegre-ES, no período de março a dezembro de 2003, utilizando-se frutos recém-colhidos de maracujazeiro (Passiflora edulis Sims f. flavicarpa Deg.).

Os frutos foram coletados na área experimental do CCA-UFES, em dois estádios de maturação: maduro, ou seja, quando apresentavam a casca totalmente amarela, e murcho. No condicionamento das sementes, metade da amostra das sementes dos frutos de cada estádio de maturação teve o arilo totalmente retirado em água corrente, sobre uma peneira de malha fina e, quando necessário, utilizou-se pano de forma a friccioná-lo entre as sementes para auxiliar na remoção. A outra metade foi lavada em água corrente, deixando-se o arilo.

A montagem do experimento foi feita no dia do corte dos frutos, e todas as sementes foram colocadas em hipoclorito de sódio a 2\%, durante 5 minutos. Em seguida as sementes foram lavadas e semeadas à profundidade de $1 \mathrm{~cm}$ em três substratos: vermiculita, areia e areia + terra + esterco (bovino) na proporção $1: 1: 1$, que foram esterilizados em estufa por 4 horas à temperatura de $160^{\circ} \mathrm{C}$. Os substratos foram colocados em placas de Petri de $9 \mathrm{~cm}$ de diâmetro, autoclavadas e a irrigação feita com água destilada conforme a observação diária de sua umidade. $\mathrm{O}$ trabalho foi conduzido em câmara de germinação (ELETROLAB®), com temperatura alternada de $20-30^{\circ} \mathrm{C}$ e fotoperíodo de 8-16 horas. Os valores das análises químicas dos substratos vermiculita e areia+terra+esterco estão representados no Quadro 1.

As avaliações foram realizadas por meio de leituras diariamente, a partir do início da germinação, até os 36 dias, tendo quantificado as porcentagens de germinação, quando foram avaliadas as plântulas normais (\%), com todas as estruturas essenciais formadas, possíveis de se desenvolverem até a formação de mudas em viveiros e as plântulas anormais, sque apresentavam deformidades;

QUADRO 1 - Composição química dos substratos vermiculita e areia + terra + esterco, utilizados no experimento.

\begin{tabular}{|c|c|c|}
\hline \multirow{2}{*}{ Composição química } & \multicolumn{2}{|c|}{ Substratos } \\
\hline & Vermiculita & Areia + Terra + Esterco \\
\hline M.O. (Dag/Kg) & 1,8 & 30,2 \\
\hline $\mathrm{pH}$ & 6,4 & 7,7 \\
\hline $\mathrm{P}\left(\mathrm{mg} / \mathrm{dm}^{3}\right)$ & 47,0 & 86,0 \\
\hline $\mathrm{K}\left(\mathrm{mg} / \mathrm{dm}^{3}\right)$ & 490,0 & 627,0 \\
\hline $\mathrm{Ca}\left(\mathrm{cmol}_{\mathrm{c}} / \mathrm{dm}^{3}\right)$ & 5,1 & 2,7 \\
\hline $\operatorname{Mg}\left(\mathrm{cmol}_{\mathrm{c}} / \mathrm{dm}^{3}\right)$ & 4,7 & 2,3 \\
\hline $\mathrm{Al}\left(\mathrm{cmol}_{\mathrm{c}} / \mathrm{dm}^{3}\right)$ & 0,2 & 0,0 \\
\hline $\mathrm{H}+\mathrm{Al}\left(\mathrm{cmol}_{\mathrm{c}} / \mathrm{dm}^{3}\right)$ & 0,8 & 0,0 \\
\hline $\mathrm{SB}\left(\mathrm{cmol}_{\mathrm{c}} / \mathrm{dm}^{3}\right)$ & 11,1 & 6,7 \\
\hline $\mathrm{t}\left(\mathrm{cmol}_{\mathrm{c}} / \mathrm{dm}^{3}\right)$ & 11,4 & 6,7 \\
\hline $\mathrm{T}\left(\mathrm{cmol}_{\mathrm{c}} / \mathrm{dm}^{3}\right)$ & 11,8 & 6,7 \\
\hline $\mathrm{m}(\%)$ & 2,56 & 0,0 \\
\hline $\mathrm{V}(\%)$ & 93,6 & 100,0 \\
\hline
\end{tabular}

SB: soma de bases; t: CTC efetiva; m: saturação de Al; T: CTC a pH 7,0 e V: saturação de bases. 
sementes duras e mortas de acordo com Brasil (1992); massa seca de parte aérea e raiz (mg) e índice de velocidade de emergência (IVE), conduzido em conjunto com o teste de germinação, obtido pela contagem do número de plântulas emergidas a partir do primeiro dia semeadura até o último dia do teste, depois aplicou-se a fórmula proposta por Maguirre (1962); massa seca da parte aérea e raiz (mg), sendo essas avaliações executadas aos 36 dias da montagem do experimento. Para essas avaliações, as plântulas foram separadas parte aérea e sistema radicular, rente ao substrato e as pesagens feitas em balança com precisão de $0,0001 \mathrm{mg}$, antes e após o material ser mantido em estufa com convecção a $80^{\circ} \mathrm{C}$ por 72 horas, ou até que o peso se mantivesse constante.

O delineamento experimental utilizado foi o inteiramente casualizado com 4 repetições de 25 sementes, em esquema fatorial $2 \times 2 \times 3$, com dois estádios de maturação do fruto (maduro e murcho), presença e ausência de arilo e três substratos (vermiculita, areia e areia + terra + esterco).

Os dados foram submetidos à análise de variância, teste de normalidade e homogeneidade, indicando a não necessidade de transformação dos dados. Posteriormente, as médias foram comparadas pelo teste de Tukey, a 5\% de probabilidade, com o auxílio do software SAEG 7.1 (SAEG, 1997).

\section{RESULTADOS E DISCUSSÃO}

Sementes provenientes de frutos murchos do maracujazeiro proporcionaram uma maior porcentagem de germinação $(82,16 \%)$ se comparado a frutos maduros, mas não murchos $(70,66 \%)$ (Figura $1 \mathrm{~A})$. O fruto se apresenta fisiologicamente maduro, de acordo com a região onde foi produzido, entre 63 e 77 dias após a antese (ALMEIDA et al., 1988; ARAÚJO et al., 1974; NACIF, 1991). Assim, Almeida et al. (1988) mostraram que sementes obtidas de frutos de 70 e 77 dias de idade eram mais vigorosas que as demais, sendo que, neste caso, o tegumento já se apresentava completamente escurecido e as sementes maduras morfológica e fisiologicamente. Possivelmente esta seria a explicação para que sementes oriundas de frutos murchos, ou seja, frutos de maior idade, apresentassem essa característica, que, conseqüentemente, determinou aumento na porcentagem de germinação das sementes. Outra possibilidade para explicar esse fenômeno seria que, nesses frutos murchos (no estádio pós-climatérico), pode ocorrer uma redução na taxa de produção autocatalítica de etileno o que, possivelmente, promoveu alguma alteração fisiológica na semente, favorecendo assim o seu processo germinativo (BUCHANAN et al., 2000; ENAMORADO et al., 1995).

Quanto à presença ou não do arilo das sementes, observa-se que houve maior porcentagem de germinação $(84,5 \%)$, quando essas sementes foram submetidas à remoção total do arilo, em comparação com as sementes com arilo (68,33\%) (Figura 1B). São José \& Nakagawa (1987) concluíram que a presença do arilo contribuiu para reduzir a porcentagem de germinação das sementes de maracujazeiro. Para a característica porcentagem de germinação não foi observada pelo teste de $F$ interação significativa entre os outros fatores estudados.

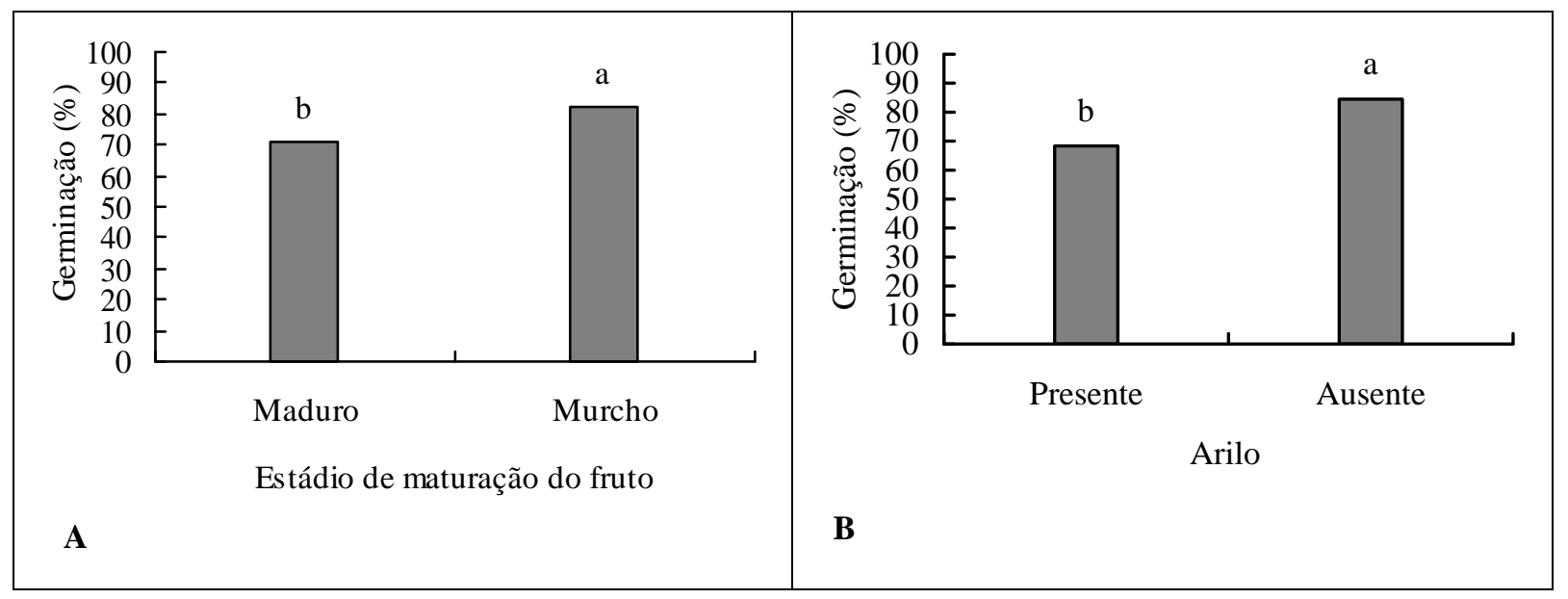

FIGURA 1 - Germinação (\%) de sementes do maracujazeiro, em função do estádio de maturação dos frutos (A) e do arilo (B). 
O Quadro 2 mostra os resultados obtidos para IVE, evidenciando que sementes com arilo, oriundas de frutos maduros, apresentaram maior IVE quando semeadas no substrato vermiculita, não diferindo estatisticamente do substrato areia + terra + esterco. Os substratos vermiculita e areia + terra + esterco (bovino), neste caso, principalmente por conter na mistura o esterco bovino, têm como principal característica à retenção de umidade, fator este considerado como fundamental ao processo germinativo (FERNANDES et al., 1983; PRIMAVESI, 1982). Já para sementes oriundas de frutos maduros e desprovidas de arilo, não se verificou diferença estatística entre todos os substratos estudados.

Sementes de frutos murchos com arilo apresentaram um maior IVE, quando semeadas no substrato areia + terra + esterco, não diferindo, entretanto, significativamente do substrato areia. Há evidências de que em frutos com maior idade, as substâncias inibidoras da germinação, poderiam estar presentes no arilo das sementes e interferir neste processo foram exauridas. Entretanto, para as sementes de frutos murchos e sem arilo, o maior IVE foi encontrado quando as mesmas foram semeadas no substrato vermiculita, sem, contudo diferir estatisticamente do substrato areia + terra + esterco (Quadro 2).

Analisando o substrato vermiculita, observou-se que as sementes oriundas de frutos maduros e murchos, com ou sem arilos, não apresentaram diferença significativa quanto ao IVE. Para os substratos areia e areia + terra + esterco, apenas as sementes de frutos maduros e murchos com arilo apresentaram diferença estatística, sendo que, sementes de frutos murchos apresentaram maior IVE.
Almeida et al. (1988) relatam que sementes provenientes de frutos com maior idade apresentam maior vigor, já que as sementes são consideradas maduras morfologicamente, o que é corroborado pelos resultados obtidos no presente trabalho para frutos murchos.

Maior porcentagem de plântulas normais $(70,0 \%)$ foi obtida de sementes procedentes de frutos murchos, resultando em menor porcentagem de plântulas anormais (12,16\%) (Quadro 3). A ausência do arilo nas sementes também proporcionou a formação de um maior número de plântulas normais. Com relação às sementes duras (Quadro 3), verifica-se que as sementes oriundas de frutos murchos apresentaram reduzida porcentagem de sementes com essa característica. Além disso, as sementes desprovidas do arilo foram as que apresentaram uma menor porcentagem de dureza. Esses resultados evidenciam a possibilidade de existir algum mecanismo no arilo dessas sementes que favoreceu a dureza nas sementes. Quanto ao conteúdo de massa seca de parte aérea (Quadro 3), as plântulas provenientes de sementes de frutos murchos foram as que apresentaram os melhores resultados.

Sementes com arilo apresentaram não somente uma maior porcentagem de sementes duras (Quadro 3), mas também maior quantidade de sementes mortas (deterioradas) se comparadas às sementes que tiveram o arilo removido, quando plantadas nos substratos vermiculita e areia (Quadro 4). Para o substrato areia + terra + esterco não se verificou diferença significativa quanto à porcentagem de sementes mortas, quando estas tiveram ou não o arilo removido (Quadro 4).

QUADRO 2 - Índice de velocidade de emergência (IVE) das sementes de maracujazeiro, em função do estádio de maturação do fruto (EMF), do arilo e do substrato.

\begin{tabular}{|c|c|c|c|c|c|}
\hline \multirow{6}{*}{ IVE } & \multirow{2}{*}{ EMF } & \multirow{2}{*}{ Arilo } & \multicolumn{3}{|c|}{ Substratos } \\
\hline & & & $\mathrm{V}^{1}$ & $\mathbf{A}^{2}$ & $\mathbf{A}+\mathbf{T}+\mathbf{E}^{3}$ \\
\hline & \multirow{2}{*}{ Maduro } & Presente & $0,8295 \mathrm{Aa}$ & $0,3805 \mathrm{Bb}$ & $0,5752 \mathrm{ABb}$ \\
\hline & & Ausente & $1,0792 \mathrm{Aa}$ & 0,8970 Аа & $0,9021 \mathrm{Aa}$ \\
\hline & \multirow{2}{*}{ Murcho } & Presente & $0,8687 \mathrm{Bb}$ & $0,9226 \mathrm{ABa}$ & 1,3316 Aa \\
\hline & & Ausente & $1,3311 \mathrm{Aa}$ & $0,7688 \mathrm{Ba}$ & $1,0199 \mathrm{ABa}$ \\
\hline
\end{tabular}

${ }^{1}$ Vermiculita $;{ }^{2}$ Areia $;{ }^{3}$ Areia + terra + esterco

Médias seguidas pela mesma letra, maiúscula na linha e minúscula na coluna, não diferem entre si pelo teste de Tukey, ao nível de $5 \%$ de probabilidade. 
QUADRO 3 - Plântulas normais e anormais (\%), sementes duras (\%) e massa seca de parte aérea (mg), em função do estádio de maturação do fruto e do arilo das sementes do maracujazeiro.

\begin{tabular}{|lcccccc|}
\hline \multirow{2}{*}{ Características avaliadas } & \multicolumn{2}{c}{ Estádio de maturação do fruto } & & \multicolumn{2}{c|}{ Arilo } \\
\cline { 2 - 3 } \cline { 5 - 6 } & Maduro & Murcho & & Presente & Ausente \\
\hline Plântulas normais & $48,33 \mathrm{~b}$ & $70,00 \mathrm{a}$ & & $52,33^{1} \mathrm{~b}$ & $66,50 \mathrm{a}$ \\
Plântulas anormais & $21,83 \mathrm{a}$ & $12,16 \mathrm{~b}$ & & - & - \\
Sementes duras & $16,08 \mathrm{a}$ & $4,50 \mathrm{~b}$ & & $12,91 \mathrm{a}$ & $7,66 \mathrm{~b}$ \\
Massa seca de parte aérea & $6,97 \mathrm{~b}$ & $7,62 \mathrm{a}$ & & - & - \\
\hline
\end{tabular}

Médias seguidas pela mesma letra, maiúscula na linha, não diferem entre si pelo teste de Tukey, ao nível de 5\% de probabilidade.

QUADRO 4 - Sementes deterioradas (\%) e massa seca de parte aérea e raízes (mg), em função do substrato e do arilo das sementes do maracujazeiro.

\begin{tabular}{|c|c|c|c|}
\hline \multirow{2}{*}{ Características Avaliadas } & \multirow{2}{*}{ Substratos } & \multicolumn{2}{|c|}{ Arilo } \\
\hline & & Presente & Ausente \\
\hline \multirow{3}{*}{ Sementes deterioradas } & Vermiculita & $24,50 \mathrm{Aa}$ & $7,50 \mathrm{Ba}$ \\
\hline & Areia & $22,25 \mathrm{Aa}$ & $4,50 \mathrm{Ba}$ \\
\hline & Areia + Terra + Esterco & $9,50 \mathrm{Ab}$ & $11,50 \mathrm{Aa}$ \\
\hline \multirow{3}{*}{ Massa seca de parte aérea } & Vermiculita & $6,74 \mathrm{Bb}$ & $8,20 \mathrm{Aa}$ \\
\hline & Areia & $6,49 \mathrm{Ab}$ & $6,19 \mathrm{Ab}$ \\
\hline & Areia + Terra + Esterco & $9,31 \mathrm{Aa}$ & $6,85 \mathrm{Bb}$ \\
\hline \multirow{3}{*}{ Massa seca de raízes } & Vermiculita & $1,24 \mathrm{Ab}$ & 1,57 Aa \\
\hline & Areia & $1,96 \mathrm{Aa}$ & $1,92 \mathrm{Aa}$ \\
\hline & Areia + Terra + Esterco & $2,34 \mathrm{Aa}$ & $1,64 \mathrm{Aa}$ \\
\hline
\end{tabular}

Médias seguidas pela mesma letra maiúscula na linha e minúscula na coluna, não diferem entre si pelo teste de Tukey, ao nível de $5 \%$ de probabilidade.

As sementes que foram mantidas com o arilo e que foram semeadas no substrato areia + terra + esterco apresentaram uma menor porcentagem de sementes mortas. Neste caso, a presença do arilo nas sementes possivelmente possibilitou o ataque de microrganismos a essa região, não afetando diretamente a semente e, conseqüentemente, reduzindo a porcentagem de sementes mortas. Mas para as sementes que tiveram o arilo removido, não se verificaram diferenças quando plantadas em todos os substratos quanto à porcentagem de sementes mortas (Quadro 4).

Plântulas oriundas de sementes desprovidas de arilo apresentaram uma maior massa seca de parte aérea, quando semeadas no substrato vermiculita. Por outro lado, sementes com arilo semeadas no substrato areia + terra + esterco apresentaram valores de massa seca da parte aérea maiores do que nos substratos vermiculita e areia. No primeiro caso, o ataque de microrganismos às sementes possivelmente foi em menor proporção possibilitando com isso melhor desenvolvimento inicial dessas plântulas. Mesmo sabendo que o substrato areia + terra + esterco apresenta maior possibilidade de ataque por microrganismos, nesta situação, temos a presença do arilo nas sementes que é considerado uma barreira ao contato imediato com a semente, ou seja, a presença de matéria orgânica nesta mistura ajuda a decomposição das 
sementes, logo após ter ocorrido provavelmente o ataque de microrganismos ao arilo. Além disso, esses resultados podem ser interpretados com base no Quadro 1 , em que a mistura areia + terra + esterco apresentou maiores valores de matéria orgânica e fósforo, e teores suficientes de cálcio e magnésio para o desenvolvimento das plântulas. Para o substrato areia não se verificou diferença significativa quanto a massa seca de parte aérea de plântulas oriundas de sementes com ou sem arilo (Quadro 4).

Quanto à massa seca de raízes, para todos os substratos estudados não se verificou diferença nas sementes com ou sem arilo. Sementes com arilo, semeadas no substrato areia e areia + terra + esterco, originaram plântulas que apresentaram uma maior massa seca de raízes. Para as sementes sem o arilo não se verificou diferença significativa quando semeadas em todos os substratos avaliados (Quadro 4).

\section{CONCLUSÕES}

Sementes obtidas de frutos de maracujazeiro com maior idade (frutos murchos) apresentam maior porcentagem de germinação e de plântulas normais.

A remoção completa do arilo das sementes favorece a porcentagem de germinação e reduz o número de sementes duras.

A velocidade de emergência de plântulas é favorecida pelo plantio de sementes de frutos murchos com arilo no substrato areia + terra + esterco.

\section{REFERÊNCIAS BIBLIOGRÁFICAS}

ALMEIDA, A. M.; NAKAGAWA, J.; ALMEIDA, R. M. Efeito do armazenamento na germinação de sementes de maracujá amarelo de diferentes estádios de maturação: experimento I. In: CONGRESSO BRASILEIRO DE FRUTICULTURA, 9., 1988, Campinas. Anais... Campinas: SBF, 1988. p. 603-608.

ARAUJO, C. M.; GAVA, A. J.; ROBS, P. G.; NEVES, J. F.; MAIA, P. C. B. Características industriais do maracujá (Passiflora edulis var. flavicarpa) e maturação do fruto. Pesquisa Agropecuária Brasileira, Brasília, v. 9, n. 9, p. 65-69, 1974.

BRASIL. Ministério da Agricultura e Reforma Agrária. Regras para análise de sementes. Brasília, DF: SNDP/ DNDV/CLAV, 1992. 365 p.
BUCHANAN, B. B.; GRUISSEN, W.; JONES, R. L. Biochemistry and molecular biology of plants. Rockville: American Society of Plant Physiologists, 2000. 1367 p.

CARDOSO, G. D.; TAVARES, J. C.; FERREIRA, R. L. F.; CÂMARA, F. A. A.; CARMO, G. A. Desenvolvimento de mudas de maracujazeiro-amarelo obtidas de sementes extraídas por fermentação. Revista Brasileira de Fruticultura, Cruz das Almas, v. 23, n. 3, p. 639-642, 2001.

CARVALHO, N. M.; NAKAGAWA, J. Sementes: ciência, tecnologia e produção. 4. ed. Jaboticabal: FUNEP, 2000. 588 p.

ENAMORADO, H. E. P.; FINGER, F. L.; BARBOSA, R. S.; PUSCH-MANN, R. Development and ripening of yellow passion fruit. Journal of Horticulture Science, London, v. 70, n. 4, p. 573-576, 1995.

FERNANDES, P. S.; BAENA, E. S.; COUTINHO, C. J.; GONÇALVES, J. C. Utilização da vermiculita no plantio de essências florestais. Silvicultura, [S.1.], v. 28, n. 1/2, p. 285 286, 1983.

MAGUIRE, J. D. Speed of germination-aid in selection and evolution for seedling emergence and vigor. Crop Science, Madison, v. 2, n. 2, p. 176-177, 1962.

MELETTI, L. M.; MAIA, M. L. Maracujá: produção e comercialização em São Paulo. Campinas: Instituto Agronômico, 1999. 64 p. (Boletim técnico, 181).

NACIF, S. R. Ontogenia e crescimento do fruto de maracujá-amarelo (Passiflora edulis var.flavicarpa). 1991. 60 f. Dissertação (Mestrado) - Universidade Federal de Viçosa, Viçosa, 1991.

PEREIRA, K. J. C.; DIAS, D. C. F. Germinação e vigor de sementes de maracujá-amarelo (Passiflora edulis Sims f. flavicarpa Deg.) submetidas a diferentes métodos de remoção da mucilagem. Revista Brasileira de Sementes, Brasília, v. 22, n. 1, p. 288-291, 2000.

PRIMAVESI, A. M. Manejo ecológico do solo. Porto Alegre: Centaurus, $1982.184 \mathrm{p}$.

SAEG. Sistema para análises estatísticas e genéticas. Versão 7.1. Viçosa: UFV/FUNARBE, 1997. 
SANTOS, C. M.; SOUZA, G. R. L.; SILVA, J. R.; SANTOS, V. L. M. Efeitos da temperatura e do substrato na germinação da semente de maracujá (Passiflora edulis Sims f. flavicarpa Deg.). Revista Brasileira de Sementes, Brasília, v. 21, n. 1, p. 1-6, 1999.

SÃO JOSÉ, A. R.; NAKAGAWA, J. Efeitos da fermentação e secagem na germinação de sementes de maracujá- amarelo. Revista Brasileira de Sementes, Brasília, v. 9, n 2, p. 35-43, 1987.

SILVA, R. P.; PEIXOTO, J. R.; JUNQUEIRA, N. T. V. Influência de diversos substratos no desenvolvimento de mudas de maracujazeiro azedo (Passiflora edulis Sims f. flavicarpa Deg.). Revista Brasileira de Fruticultura, Cruz das Almas, v. 23, n. 2, p. 377-381, 2001. 